\title{
Reisestipendium 2019 der Deutschen AO
}

Karl-Heinz Frosch

\section{Anträge auf das AOTrauma Deutschland-Reisestipendium 2019 können bis Don- nerstag, 31. Januar 2019 eingereicht werden.}

Die AOTrauma Deutschland vergibt jährlich mindestens ein Reisestipendium zur Förderung des Erfahrungsaustausches und der Weiterbildung bei angesehenen Experten in unserer Disziplin. Der Maximalbetrag pro Stipendium beträgt 5000 EUR. Bewerben können sich klinisch aktive Mitglieder der deutschen AOTrauma, AOCMF und AOVET (Eintritt ist bis Bewerbungsfristende möglich). Einzureichen sind ein Motivationsschreiben (max. 1 Seite), der Name der zu besuchenden Klinik und des Arztes sowie ein Kurz-CV. Nach Abschluss der Reise ist ein kurzer Bericht zu schreiben. Eine Auswahlkommission wird die Entscheidung treffen.

Berichte über vergangene Reisestipendien finden Sie auf der AOTrauma Deutschland-Website: www.aotrauma.org/Deutschland

Anträge können eingereicht werden bis zum 31. Januar (Poststempel oder E-Mail-Eingang vor Mitternacht am 31.01.2019) bei:

Univ.-Prof. Dr. Karl-Heinz Frosch

AOTD Community Development Officer

Klinik für Unfall, Hand- und Wiederherstellungschirurgie Universitätsklinikum Hamburg-Eppendorf

Martinistraße 52

20246 Hamburg

E-Mail: k.frosch@uke.de

Bibliografie

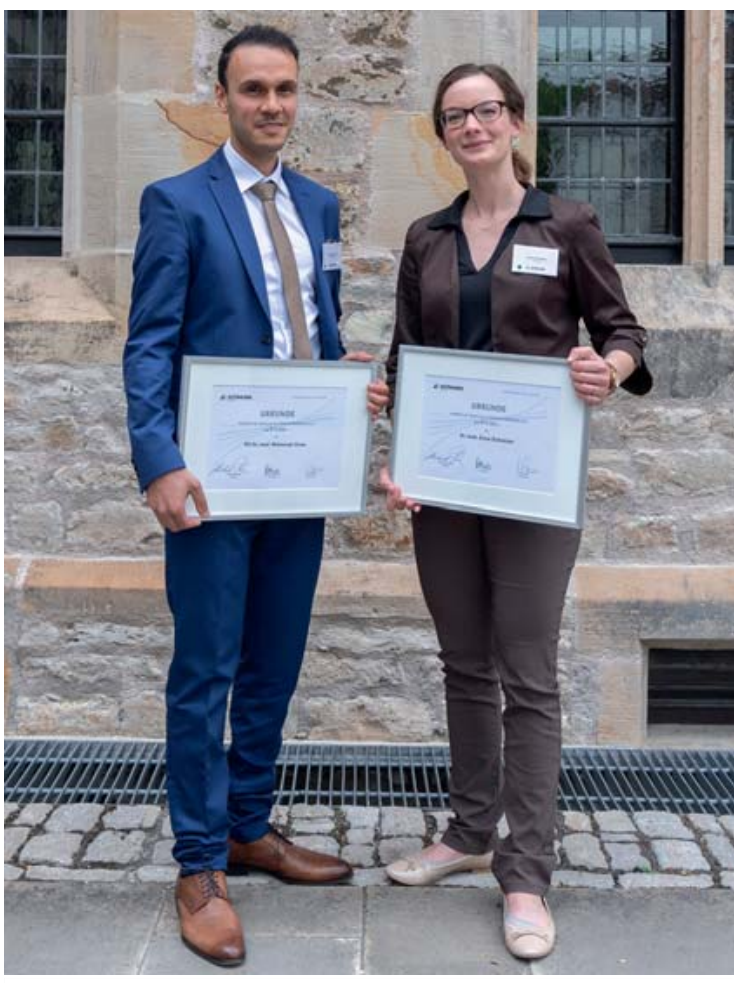

- Abb. 1 Die Reisestipendiaten Mohammad Omar und Anna Schreiner. (c) AO Foundation

DOI https://doi.org/10.1055/a-0749-4642

OP-JOURNAL 2018; 34: 346 @ Georg Thieme Verlag KG Stuttgart · New York ISSN 0178-1715 